\title{
PROGRAMA PRÓ-LETRAMENTO EM ABAETETUBA: AVANÇOS NO ENSINO DA MATEMÁTICA SIGNIFICATIVA
}

\author{
Benedita das Graças Sardinha da SILVA ${ }^{1}$ \\ SEMEC/Abaetetuba \\ sardinhadousj@yahoo.com.br \\ Marinilda Correa SARDINHA ${ }^{2}$ \\ SEMEC/Abaetetuba \\ nilda_correa16@hotmail.com
}

Resumo: Este artigo pretende discorrer sobre a práxis dos docentes que participaram do Programa de Formação Continuada Pró-Letramento, ocorrido nos anos de 2011 e 2012, no município de Abaetetuba-Pará, destinado a professores efetivos que atuam nos anos iniciais do Ensino Fundamental na zona rural: região das ilhas e ramais. A metodologia adotada tem fundamentos na análise documental, em que serão utilizados os dados obtidos a partir de instrumentos de registro dos cursistas, como o portfólio e alguns de seus comentários realizados durante a execução do curso. A partir da análise, criteriosa, dessas informações, constatou-se que o programa influenciou, significativamente, em sua forma de atuação, uma vez que a formação do PróLetramento proporcionou a busca do saber e a reflexão das práticas docentes, conduzindo a tomadas de decisão frente aos desafios da proposta do programa, uma vez que trouxe novos paradigmas para o processo ensino aprendizagem da matemática.

Palavras-chave: Pró-Letramento. Formação continuada. Ensino de matemática.

Abstract: This article aims to discuss about praxis of teachers who participated of Continued Formation Program Pro-literacy occurred in the years 2011 and 2012 in the city of Abaetetuba Pará, destined for effective teachers who work

\footnotetext{
${ }^{1}$ Mestranda do Programa de Pós-graduação em Educação da Universidade do Estado do Pará. Professora de Educação Básica da Prefeitura Municipal de Abaetetuba.

${ }^{2}$ Especialista em Gestão, Orientação e Supervisão Escolar. Professora da Educação Básica da Prefeitura Municipal de Abaetetuba.
} 
in the early years of basic education in countryside: islands region and extensions. The methodology has foundations in document analysis, which will be used in the data obtained from recording instruments of the course participants, as the portfolio and some of his comments made during the execution of the course. From the analysis, careful, this information, it was found that the program influenced significantly in the form of acting since the formation of the Pro - Literacy provided the search for knowledge and reflection of teaching practices leading to decision-making facing the challenges of the propose program since brought new paradigms for teaching learning process of mathematics.

Keywords: Pro-Literacy. Continued formation. Teaching of mathematics.

\section{Introdução}

O presente trabalho apresenta uma discussão a respeito da práxis dos docentes cursistas participantes do Programa de Formação Continuada para Professores - Pró-Letramento - voltado para o ensino de Matemática nos anos iniciais. Buscou-se discorrer a respeito desta temática por entender que muitos são os Programas criados pelo Ministério da Educação (MEC) voltados para a formação de professores, contudo pouco se produz e/ou registra a respeito, no sentido de divulgar o grau de satisfação dos partícipes dessas formações.

O estudo da receptividade dos cursistas ao programa é de grande relevância para análise do melhoramento do ensino de matemática em sua sala e das influências que foram visualizadas no aprendizado de seus alunos, partindo do seguinte problema: Quais as contribuições que o Programa Pró-Letramento trouxe para o fazer docente dos professores cursistas, no município de Abaetetuba na disciplina Matemática?

A prefeitura do município de Abaetetuba aderiu ao Programa Federal Pró-letramento nos anos de 2011 e 2012 e teve como públicoalvo uma clientela de 321 cursistas, na primeira fase, e atualmente, no revezamento, conta com 284, sendo 142 na área de Linguagem e 142 em Matemática. Os cursistas de matemática são oriundos das 


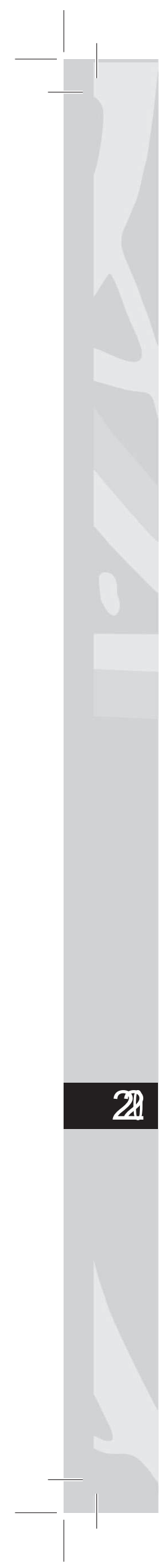

72 ilhas que compõem o município como das 46 escolas dos ramais e vicinais, que a cada encontro deixam suas comunidades para se deslocar à sede do município onde é ofertada a Formação.

Tal formação ocorre na Escola Municipal Dr. Vicente Maués, que possui um espaço amplo e oferece boas condições, o que favorece a formação. São utilizadas seis salas de aula, sendo 03 (três) de Linguagem e 03 (três) de Matemática. A Gestora da Escola tem colaborado bastante, colocando à disposição alguns profissionais que ajudam nas atividades de apoio.

Deve-se destacar também a parceria da Secretaria Municipal de Educação, que é a promotora do evento, e tem como coordenadora geral a Diretora de Ensino Marineide Ribeiro; e as tutoras da área de Matemática Benedita das Graças Sardinha, com 47 cursistas; Elizeth Caripuna Gomes, com 47 cursistas, e Gecilene Cardoso do Rêgo, com 48 cursistas.

Os cursistas, em sua grande maioria, atuam com classes multisseriada - classe com duas ou mais séries simultaneamente -, o que justifica seus esforços em participar da formação, pois a singularidade desta clientela exige do docente a variação metodológica que possam contemplar a todos os alunos.

Aqui se pretende tratar de alguns conceitos e traçar algumas discussões referentes aos aportes teóricos e conceituais que darão embasamento e sustentação a esta pesquisa. Inicialmente será pontuada uma discussão sobre Programa Pró-Letramento na formação continuada, destacando sua importância para o melhoramento da ação docente e sua finalidade na Educação Matemática. E por fim, elencar os relatos de experiências dos docentes que fizeram parte do programa nos anos de 2011 e 2012, buscando evidenciar suas impressões frentes às mudanças ocorridas em sua prática pedagógica.

\section{Formação Continuada}

O conhecimento se tornou moeda de troca no modelo de sociedade em que vivemos atualmente, uma vez que é imprescindível para a vida social e direciona o caminho para o exercício do agir, 
perante as situações do mundo contemporâneo. A escola é um dos veículos responsáveis pelo acesso ao conhecimento formal e, consequentemente, pela formação de cidadãos atuantes na prática social.

Em virtude dessas transformações sofridas pela sociedade, as instituições de ensino também precisam atualizar seus métodos e técnicas de ensino, na tentativa de enriquecer o fazer docente e proporcionar aos alunos um melhor aprendizado das diversas áreas do conhecimento, em sala de aula.

Desse modo, todos os profissionais que atuam na educação, cada um com as suas incumbências, são responsáveis pelo aprendizado dos alunos, contudo, o professor possui uma responsabilidade maior nesse processo. São inúmeros fatores subjacentes ao ensino que exigem do professor uma diversidade de saberes que possam contribuir para que seu fazer pedagógico seja desenvolvido com sucesso diante da diversidade de seus alunos.

Tais saberes, sejam eles teóricos ou práticos, devem ser, constantemente, atualizados, e a formação continuada ainda é a melhor opção para garantir que esses profissionais da educação melhorem suas potencialidades de atuação.

Para atingir tal finalidade, os governos federal, estadual e municipal, por meio de parcerias e convênios implantam iniciativas de formação para os professores, sejam elas em nível de graduação, capacitação ou formação continuada, de acordo como postula a LDB (9394/96) em seu artigo 62:

$\$ 1^{\circ}$ A União, o Distrito Federal, os Estados e os Municípios, em regime de colaboração, deverão promover a formação inicial, a continuada $e$ a capacitação dos profissionais do magistério.

$\$ 2^{\circ}$ A formação continuada e a capacitação dos profissionais do magistério poderão utilizar recursos $e$ tecnologias de educação a distância.

Esses cursos de formação de professores, além de fornecer embasamento teórico, ampliam sua formação inicial, proporcionando 


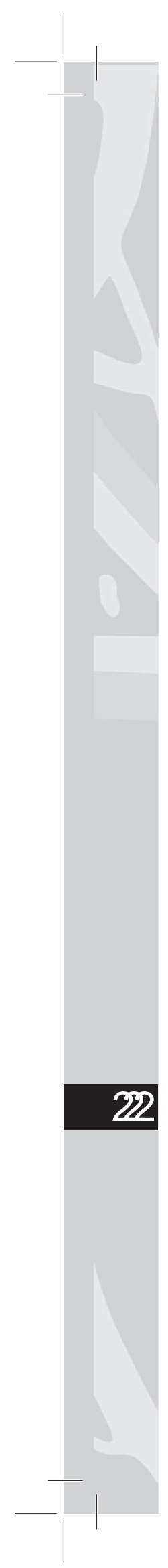

o exercício da docência, por meio de metodologias alternativas, visando facilitar e auxiliar o processo de construção do conhecimento por parte dos alunos.

Iniciativas como essas trazem à tona a discussão a respeito de que os profissionais da docência devem ir muito além da simples tarefa de ensinar. Devem se preocupar, sobretudo, com os aspectos que norteiam e influenciam na aprendizagem dos alunos, inovando e explorando novas formas de ensinar, a fim de contribuir para o seu êxito e progresso nos estudos.

De acordo com Veiga (2008, p. 14):

A docência requer formação profissional para seu exercício: conhecimentos específicos para exercêlo adequadamente ou, no mínimo, a aquisição das habilidades e dos conhecimentos vinculados à atividade docente para melhorar sua qualidade. Outra característica da docência está ligada à inovação quando rompe com a forma conservadora de ensinar, aprender, pesquisar e avaliar [...] explora novas alternativas teórico-metodológicas em busca de outras possibilidades de escolha.

Por outro lado, buscar formação continuada não é uma tarefa simples nem pouco cansativa. Exige muita disposição e persistência, pois muitos dos cursos ofertados ocorrem aos finais de semana ou em período simultâneo aos dias letivos de trabalho, tendo o profissional que se desdobrar para cumprir com seus compromissos e destinar um tempo para se atualizar.

Neste sentido, a busca da qualificação não representa um atrativo a todos os profissionais da educação, destina-se àqueles que entendem a importância de pleitear melhorias para seu trabalho e que estão dispostos a abrir mão de alguns momentos de repouso em sua dura jornada. Segundo Tardif e Lessard (2008, p. 113):

como em qualquer outra profissão, alguns professores fazem exata e unicamente o que é previsto pelas normas oficiais da organização escolar, ao passo que 
outros se engajam a fundo num trabalho que chega a tomar um tempo considerável até mesmo invadindo sua vida particular, as noites, o fim de semana, sem falar das atividades de duração mais longa, como cursos de aperfeiçoamento, de formação específica, atividades paraescolares ou sindicais, das associações profissionais.

Ser professor, em tempos atuais, requer um profissional que saiba desenvolver competências básicas, como a capacidade de abstração, desenvolvimento do pensamento sistêmico, ao contrário da compreensão parcial e fragmentada dos fenômenos; que intervenha em seu contexto educacional, isto é, que identifique as forças e as fraquezas, sendo o mediador da interação do sujeito com os objetos do conhecimento e com os sujeitos do meio; que sejam possuidores da criatividade, da capacidade de pensar múltiplas alternativas para a solução de um problema; que apresente condições de trabalhar em equipe, visando à gestão democrática, que contribuirá para o desenvolvimento do pensamento crítico.

Tais características se constroem a partir da confiança e do amor que o profissional deposita em suas relações com as pessoas e em seu aprendizado, uma vez que a formação continuada oportuniza aos docentes entrarem em contato com a parte conceitual, atitudinal, factual e procedimental da matemática de forma prática, por meio da utilização do material concreto e assim formalizar um conhecimento significativo.

Ao professor cabe o papel de proporcionar o aumento e o fortalecimento de habilidades de resolução de problemas e a aprendizagem de novas estratégias, bem como auxiliar os estudantes que apresentam dificuldades. Além disso, faz-se necessário que este profissional reflita a respeito de como a formação continuada é traduzida em sua vida, no sentido de promover melhoras em sua qualidade de trabalho e no confronto com os saberes da formação inicial, com os valores, com a capacidade de lidar com os novos paradigmas educacionais, além de despi-lo de suas convicções das práticas por anos praticadas. 


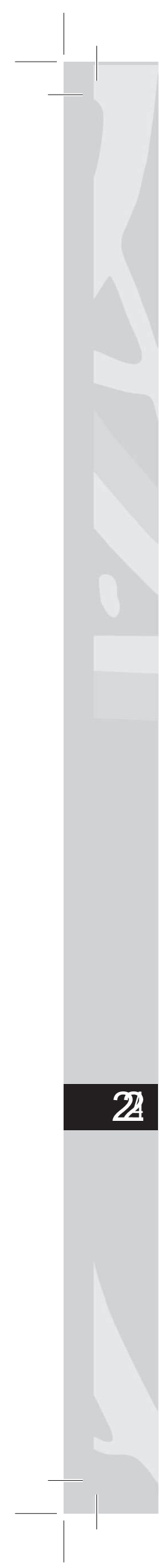

O grande desafio do tutor é conseguir ampliar as habilidades dos cursistas, no sentido da progressão individual e penetrar no universo cognitivo e afetivo, e mostrar que os desafios que eles enfrentam são essenciais para seu desenvolvimento profissional e que devem ser resistentes às dificuldades e procurar transpô-las.

Paulo Freire (1996) admoesta quanto à práxis pedagógica que "Saber ensinar não é transferir conhecimento, mas criar as possibilidades para a sua própria produção ou a sua construção". E isto é algo que os educadores precisam cultivar em sua vida e em seu fazer docente, pois há momentos em que as palavras não resolvem e os gestos valem mais; gestos que são interpretados por aqueles que os vêm como modelos de cidadãos, que acreditam em sua capacidade de transpor as faltas do sistema social em que vivem.

Além disso, no âmbito da discussão, há professores que apresentam maior resistência aos fatores agressores encontrados na prática, criando alternativas para contornar os desafios e responder às dificuldades, reagindo às adversidades e mostrando-se capazes de criar alternativas para transformar as informações em conhecimentos. "O educador que escuta aprende a difícil lição de transformar o seu discurso, às vezes necessário ao aluno, em uma fala com ele”. Freire (1996, p. 139).

Neste sentido, a ação docente consolida-se com a valorização, pelo próprio professor, da importância de fortalecer a articulação dos diversos interesses envolvidos no seu contexto de atuação em direção a uma atitude dialógica, criticamente ética e flexível, participativa e colaborativa, que permita tomadas de decisões, reflexão sobre elas, construção de conhecimento docente, investigações e, ao mesmo tempo, crie o ambiente com suporte afetivo e emocional necessário para se trabalhar com os alunos.

Assim, o fazer docente requer múltiplas habilidades por parte do professor. Tais habilidades são adquiridas por meio da pesquisa, da atualização dos saberes e do entendimento de que a formação continuada deve ser uma prioridade, visto que é de suma importância para o desenvolvimento de novas estratégias metodológicas de ensino 
e é o principal meio para colaborar para a eficácia do trabalho do professor que, de fato, está preocupado com a aprendizagem de seus alunos.

\section{O Pró-Letramento e a formação continuada}

O Programa de Formação Continuada Pró-Letramento é um programa do governo federal destinado a professores que estão atuando no Ensino Fundamental que possuam vínculo efetivo com as prefeituras. De acordo com a definição dada pelo fascículo do PróLetramento em Matemática (2008, p. 7):

O Pró-Letramento é um programa de formação continuada de professores [...] realizado pelo MEC com a parceria de universidades que integram a Rede Nacional de Formação Continuada e com adesão dos estados e municípios. Podem participar todos os professores que estão em exercício nas séries iniciais do ensino fundamental das escolas públicas.

Quanto a Rede Nacional de Formação Continuada de Professores, o portal do Ministério da Educação e Cultura (MEC, s.p.), esclarece que:

foi criada em 2004 com o objetivo de contribuir para a melhoria da formação dos professores e alunos. $O$ público-alvo prioritário da rede são professores de educação básica dos sistemas públicos de educação. As instituições de ensino superior públicas, federais e estaduais que integram a Rede Nacional de Formação de professores, produzem materiais de orientação para cursos a distância e semipresenciais, com carga horária de 120 horas. Assim, elas atuam em rede para atender às necessidades e demandas dos sistemas de ensino. As áreas de formação são: alfabetização e linguagem, educação matemática e científica, ensino de ciências humanas e sociais, artes e educação física. O Ministério da Educação oferece suporte técnico e financeiro $e$

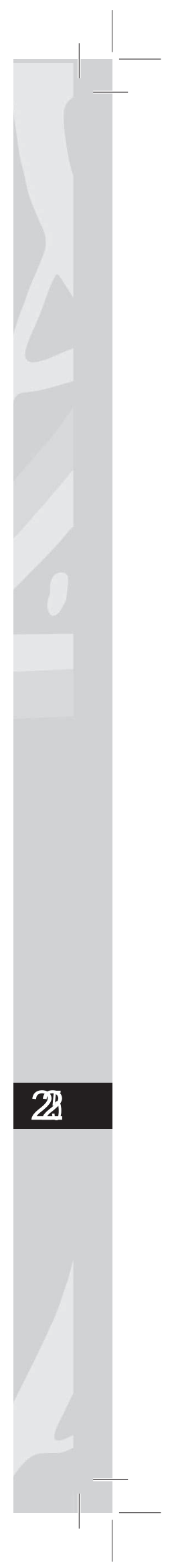


tem o papel de coordenador do desenvolvimento do programa, que é implementado por adesão, em regime de colaboração, pelos estados, municípios e Distrito Federal.

Os objetivos do programa são, entre outros:

\begin{abstract}
Oferecer suporte à ação pedagógica dos professores dos anos/séries iniciais do ensino fundamental, contribuindo para elevar a qualidade do ensino e da aprendizagem de língua portuguesa e matemática; desenvolver conhecimentos que possibilitem a compreensão da matemática e da linguagem e de seus processos de ensino e aprendizagem; contribuir para que se desenvolva nas escolas uma cultura de formação continuada. (Guia Geral do Pró-Letramento, 2010, p. 1)
\end{abstract}

O projeto se desenvolve em duas etapas, que se dão em dois anos consecutivos: os cursistas - nome dado aos professores que cursam o projeto - inscritos são organizados em dois grupos; um grupo cursa Matemática durante um ano, e o outro, a Alfabetização e Linguagem, com uma carga horária de 120 horas. No ano seguinte, há o revezamento, em que os cursistas que fizeram o curso de Matemática trocam de tutores, ou seja, os que estavam na Matemática se direcionam ao estudo da Alfabetização e Linguagem e os de Linguagem passarão a estudar a Matemática, recebendo também uma certificação de 120 horas correspondente a esta segunda etapa da formação.

\title{
3 Procedimentos do programa
}

O material impresso distribuído para subsidiar a execução do programa é subdividido em oito fascículos que abarcam os conteúdos de matemática que compõem o currículo do Ensino Fundamental (anos iniciais) e estão em consonância com os descritores na avaliação 
nacional Prova Brasil e com o último que trata do tema avaliação e seus instrumentos.

Em cada um dos fascículos é apresentada uma parte teórica, a qual faz uma revisão bibliográfica dos assuntos apresentados e algumas discussões acerca das hipóteses que os alunos criam, de acordo com seus conhecimentos prévios, em que o professor deve facilitar a formalização dos conceitos matemáticos, além do espaço destinado à apresentação, confecção, discussão e utilização de recursos pedagógicos que possam facilitar a compreensão dos conteúdos matemáticos.

No fascículo I, que trata de Números Naturais, foram utilizados alguns recursos pedagógicos para trabalhar contagem. Dentre eles se deu destaque à reta numérica, ao material dourado, ao varal didático, ao o maior leva, ao ábaco e ao bingo. Além disso, foi sugerida a utilização de materiais alternativos, como tampinhas de garrafas, palitos de fósforos, entre outros, dentre os quais, segundo nos relata a cursista A:

Eu nunca tinha trabalhado com reta numérica, na verdade eu nunca tinha nem visto, mas depois do encontro eu percebi que tinha atividade proposta nos livros didáticos. Sem contar o material dourado que eu pensei que era dourado mesmo, e fui ver que vem também no livro didático e aprendemos que e tão fácil ensinar por ele.

No fascículo II, cujo tema é as quatro operações, foram apresentados o ábaco, o Quadro Valor do Lugar (CAVALU), o material dourado, a escala Cuisenaire e o bingo da adição e subtração. Diante da apresentação deste fascículo, em relato do momento, pensando juntos, uma cursista, da localidade Sarapuquara, destacou sua dificuldade, desde a formação inicial, em apresentar o algoritmo de divisão e também a falta de compreensão do significado da expressão "vai um", e acrescentou "só compreendi agora quando vocês mostraram no quando valor do lugar. Vale a pena mesmo esse curso porque tira as nossas dúvidas" 
No fascículo IV, foi estudado o assunto fração, sendo apresentados a régua de fração e o disco de fração. Este foi um dos fascículos mais trabalhosos principalmente por se apresentar uma proposta de quebra do paradigma das frações equivalentes e adição e subtração de fração, por meio da classe de equivalência, em que os cursistas lamentaram não ser um curso acessível a todos, pois as mudanças atitudinais interferirão nas propostas pedagógicas dos planos de ensino. A professora B, salientou:

É uma pena que nem todos tenham conhecimento dessa forma de ensinar fração, porque eu já sei usar a equivalência para trabalhar adição e subtração, mas quem não participou do curso vai continuar ensinando pelo MMC.

No fascículo V, o assunto tratado foi Grandezas e medidas, em que foram utilizados calendários, embalagens, fita métrica, dinheirinho recortado de livros didáticos, entre outros. No portfólio da cursista C, ela destacou:

Agora eu entendi como se planeja as aulas de forma de projeto, assim dá para gente fazer porque tem significado e faz parte da nossa vida.

O VI fascículo fala de Tratamento da informação, com confecções de vários tipos de gráficos, tendo como dados idades, preferência de cor e altura dos próprios cursistas.

\section{O Cursista e o Pró-Letramento}

Esta seção se destina a descrever as impressões dos cursistas em relação ao aproveitamento do Pró-Letramento para seu fazer pedagógico, no que diz respeito à facilitação do entendimento da matemática. Será dado destaque, tanto para as falas dos professores cursistas, quanto para as dos alunos - trazidas por seus professores no momento da socialização. 
Antes, porém, não poderia deixar de destacar que no primeiro encontro foi realizada uma dinâmica com os cursistas para identificar o que os levou a se inscrever no Projeto e quais suas expectativas em relação a ele. Muitos ressaltaram que parte dos motivos que os conduziram a participar do Projeto foram suas dificuldades em trabalhar alguns conceitos matemáticos de forma concreta e que estavam esperando encontrar mecanismos que os ajudassem a sanar ou, ao menos, amenizar tais dificuldades.

\section{Relatos dos Cursistas}

A partir da análise das avaliações realizadas pelos cursistas ao final de cada fascículo, ficou evidente que a metodologia adotada pelo programa Pró-Letramento, influenciou na práxis de muitos de seus participantes. Discorreremos sobre alguns desses relatos:

As atividades desenvolvidas nos fascículos contribuíram de forma significativa para a minha prática pedagógica. Assim como os jogos e os projetos didáticos que contribuíram para tornar minhas aulas mais eficazes e estimulantes, ligando a aprendizagem ao prazer e ao divertimento (Orquidea).

De modo geral, as atividades dos fascículos foram bem satisfatórias, onde a cada estudo surtia efeito diretamente ligado a minha dinâmica em sala de aula. Tentei repassar um pouco dessa experiência do curso no meu cotidiano escolar (Edwin).

Outros docentes ressaltaram a importância do projeto para rever e dar uma nova direção a forma como trabalhavam os conteúdos matemáticos:

As atividades desenvolvidas são importantes para que o professor reveja sua prática de sala de aula e possa incorporar novos métodos e metodologias, usando a pesquisa para que possa promover um aprendizado eficaz (Evelliyn).

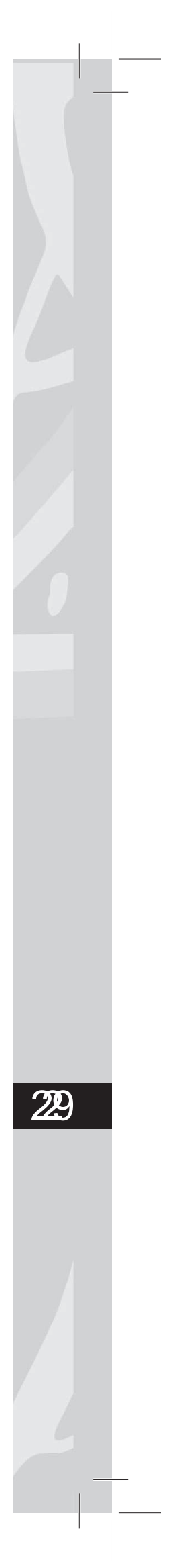


A maioria das atividades presentes nos fascículos estudados era bastante interessante e nos ajudaram a repensar a nossa prática. Todas essas atividades que desenvolvi me ajudaram a criar um ânimo novo para o desenvolvimento de novas estratégias no ensino de matemática (Aldiléia).

As atividades desenvolvidas durante os encontros foram ótimas, pois com elas pude melhorar minha prática de ensino em sala de aula. As tarefas desenvolvidas e apresentadas foram muito criativas (Sílvia).

\section{O olhar dos alunos a partir dos relatos dos professores}

A partir das falas dos professores e de suas avaliações escritas, observamos que o grande diferencial do projeto, foi que ele, efetivamente, conseguiu atingir as salas de aula, não foi somente um curso que ficou na base teórica, embora a teoria fosse parte integrante da formação. Mas, a cada fascículo estudado, eram apresentadas várias opções de recursos pedagógicos para trabalhar o assunto contido no referido fascículo.

E um dos grandes diferenciais evidenciado pelos cursistas está na possibilidade de os alunos confeccionarem e manusearem seus próprios materiais. Durante a confecção, o aluno descobre as propriedades inerentes àquele recurso, além da importância de conservar tal produção. No manuseio, aprendiam os assuntos matemáticos interagindo, bem como chegavam a suas próprias conclusões e faziam suas deduções a partir da observação e da intervenção da professora. Mesmo que imperceptível, por parte do aluno, essa forma de conduzir as aulas torna-o gerenciador de seu próprio conhecimento.

Uma das professoras destacou:

Os alunos vieram me perguntar quando a gente ia brincar de novo com a reta. Trabalhei com a idade deles na reta e eles adoraram e entenderam que ela começa com o zero, porque quando eles nasceram eles não 
tinham um ano ou um mês, eles estavam no zero. As atividades dos fascículos eram inovadoras, algo que chama a atenção dos alunos, não tinha um nivel de dificuldade excessivo. Portanto, foram desenvolvidas com tranquilidade (Ana Léa).

Outra ressaltou que quando trabalhou com o tangran os alunos fizeram uma série de figuras com suas peças e, inclusive, figuras que ela ainda não tinha mostrado:

Professora, consegui fazer sozinho uma casa. Eu já sei fazer cachorro e barco com o tangran; Eu achei bacana esse homem como se estivesse correndo, é engraçado.

Portanto, os cursistas declaram que o Programa trouxe melhoras significativas para o ensino de Matemática em suas salas de aula, com propostas de metodologias que atraem a atenção dos alunos e os instigam a estudar e aprender esta disciplina.

Ressaltam envidar esforços na tentativa de fazer com que suas formas de ensinar sejam diferenciadas. Para isso, investiram na utilização de aulas práticas com material concreto, que pudessem chamar a atenção do aluno e o auxiliasse na construção de conceitos conforme mostrado nos encontros do projeto, visto que perceberam que essa forma de atuar dá certo e surte efeito positivo para o aprendizado do aluno.

\section{Conclusão}

Pretendemos, com este trabalho, relatar a importância do Programa Pró-Letramento para a formação dos docentes e para melhoria do ensino de Matemática nos anos iniciais do município de Abaetetuba, por entender que a metodologia adotada por este programa contribuiu, efetivamente, para o melhoramento da educação dos alunos que tinham seus professores participando da formação. 


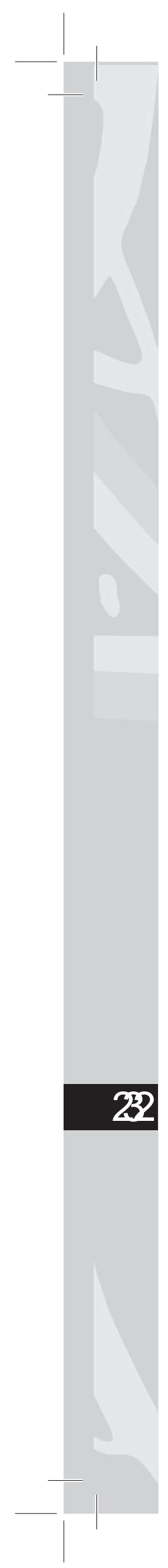

Podemos constatar que a formação contribuiu significativamente quando em nossas visitas in locus vimos salas de aula com recursos matemáticos sendo utilizados pelos alunos, bem como os materiais permanentes fixados nas paredes, tornando a sala de aula um ambiente propício à aprendizagem da matemática. Os relatos dos educandos afirmam: "Depois que a tia vem da cidade, ela traz novidade pra nós e fica mais fácil aprender a Matemática e até ela gosta mais de dá aula pra nós”.

Após análise dos instrumentos de coleta de dados, julgamos que o Programa Pró-Letramento fez a diferença no fazer docente dos professores que participaram da formação, pois contribuiu para a compreensão de que a matemática só é possível com a compreensão do significado dos conteúdos matemáticos pelas crianças, e, quando conseguirmos alcançar tal finalidade, teremos a certeza de que elas não terão medo da Matemática e poderão construir significativamente seus saberes.

\section{REFERÊNCIAS}

BRASIL. Lei de Diretrizes e Bases da Educação Nacional (LDB). Lei 9394/96. Brasília: Ministério da Educação, 1996.

Programa de Formação Continuada de Professores dos Anos/Séries iniciais do Ensino Fundamental: Matemática. Edição revisada e ampliada. Brasília: Ministério da Educação/ Secretaria de Educação Básica, 2008.

Programa de Formação Continuada de Professores dos Anos/Séries iniciais do Ensino Fundamental: Guia Geral. Brasília: Ministério da Educação/ Secretaria de Educação Básica/ Secretaria de Educação a Distância, 2010.

FREIRE, Paulo. Pedagogia da Autonomia: saberes necessários à prática educativa. 25a ed. São Paulo: Paes e Terra, 1996. 
FOSSA, John Andrew. Encontro de Pesquisa Educacional do Nordeste: Educação Matemática. Natal: EDUFRN, 1998.

MINISTÉRIO DA EDUCAÇÃO E CULTURA. Rede Nacional de Formação de Professores. Disponível: $\leq$ http://www.portal. mec.gov.br/index.php? Itemid $=457 \& i d=231 \&$ option $=$ com content\&view $=$ article $>>$. Acesso: 03/06/2012.

TARDIF, Maurice; LESSARD, Claude. O Trabalho Docente: Elementos para uma teoria da docência como profissão de interação humana. $4^{\mathrm{a}}$ ed. Petrópolis: Vozes, 2008.

VEIGA, Ilma Passos Alencastro. Docência como atividade profissional. In: VEIGA, Ilma Passos Alencastro; D'AVILA, Cristina (Org.). Profissão docente: novos sentidos, novas perspectivas. Campinas: Papirus, 2008. 